\title{
How “Dark Side” Personality Traits Affect Social Network Position
}

\author{
Mantas Bolys, Lara Kotobi, Adrian Furnham \\ Research Department of Clinical, Educational and Health Psychology, University College London, London, UK \\ Email: a.furnham@ucl.ac.uk
}

How to cite this paper: Bolys, M., Kotobi, L., \& Furnham, A. (2017). How "Dark Side" Personality Traits Affect Social Network Position. Psychology, 8, 550-562. https://doi.org/10.4236/psych.2017.84035

Received: January 27, 2017

Accepted: March 11, 2017

Published: March 14, 2017

Copyright (c) 2017 by authors and Scientific Research Publishing Inc. This work is licensed under the Creative Commons Attribution International License (CC BY 4.0).

http://creativecommons.org/licenses/by/4.0/

\begin{abstract}
This study explored how "dark side" personality traits affect social network positioning. Thirty-one working adults completed the Hogan Developmental Survey (HDS), as well as a Social Network Analysis (SNA) survey measuring friendship, advice and innovation networks. SNA measures of Indegree (popularity measure) and Outdegree (expansiveness measure) were positively associated with Excitable and Colorful personality traits. In addition, Sceptical and Diligent personality traits were negatively associated with Indegree and Betweenness Centrality (network position importance measure). Implications and limitations were discussed.
\end{abstract}

\section{Keywords}

Social Network Analysis, "Dark Side Traits”, Personality in SNA

\section{Introduction}

\subsection{Social Network Analysis}

There is a growing literature on what has been called the "dark-side" of personality (Furnham, 2015). This usually refers to sub-clinical personality disorders such as Narcissism. The focus of much of this research is the extent to which these dark-side factors lead to management failure and derailment. This study looks at the relationship networks of people as a function of their dark-side profile.

Social network analysis (SNA) attempts to investigate relationships among interacting people. The unit level of analysis in network research consists of a collection of individuals and linkages among them (Wasserman \& Faust, 2009). Instead of focusing on individual's attributes or the prediction power of those attributes, the social network perspective considers these attributes as a product of structural or relational processes. The task of network perspective is to under- 
stand how structural properties affect observed characteristics.

Social network analysis stems from Moreno's (1953) research on sociometrythe measurement of interpersonal relations of small groups. The sociogram was devised as a method to investigate. It presents a picture, in which actors (individuals in a network) are depicted as points in a two-dimensional space, while the relationships between actors are portrayed as lines (or ties) linking corresponding points. Since then, the field of SNA has advanced to study interpersonal relations of individuals in various disciplines, such as anthropology (Schweizer, 1988), sociology (Burt, 1987), management (Kim, Choi, Yan, \& Dooley, 2011), communications (Contractor \& Eisenberg, 1990), and social psychology (Wrzus, Hänel, Wagner, \& Neyer, 2013).

\subsection{Social Network Analysis and Personality}

Social network research has primarily focused on the influence of observable individual attributes such as gender or explaining social networks through homophily phenomena (the tendency to associate with similar others). However, there is limited research exploring how individual psychological characteristics may be associated with personal network characteristics (Kalish \& Robins, 2006; Mehra, Kilduff, \& Brass, 2001). This is mainly because social network research is mostly concerned with the structure and effects of relations between people, groups or organisations (Brass, Galaskiewicz, Greve, \& Tsai, 2004; Tichy, Tushman, \& Fombrun, 1979) rather than psychological dimensions of individuals.

Burt, Jannota, \& Mahoney (1998) were probably the first to integrate personality research in SNA methodology. The authors investigated whether personality traits vary systematically with "structural holes", which is defined as nonredundant information that is contained by two separate structures/“cliques". The results indicated that people with the least constrained networks (entrepreneurial networks) had a tendency to seek advice from their colleagues (accuracy of information), perceived themselves to be in a position of authority (independence) and were able to create an aura of excitement (persuasion). The findings were in line with a study by Kalish \& Robins (2006). They showed that people who were more individualistic, more controlling, and more neurotic tended to occupy structural hole positions.

Klein, Lim, Saltz, \& Mayer (2004) used the Big Five Factor Model (Goldberg, $1990)$ to predict SNA's structures. Their study showed that highly educated individuals with low Neuroticism scores secured central positions in advice and friendship networks. However, Openness to Experience was negatively associated with friendship centrality and correlated positively with adversarial centrality. Similar findings were obtained in Kanfer \& Tanaka's (1993) study with students. They found that the more Extraverted, Agreeable, and Emotionally stable individuals were better connected in a network. More recently, Zhu, Woo, Porter, \& Brzezinski (2013) demonstrated that Extraversion, Agreeableness and Openness scores positively predict SNA characteristics such as the network size, upper reachability and proportion of new contacts. 


\subsection{Dark Side Personality and Social Networks}

There has been an increase interest in so-called "dark side personality", which is defined as dysfunctional dispositions that influence one's behaviour and thinking (Hogan \& Hogan, 2001). The Hogan Development Survey (HDS; Hogan \& Hogan, 1997) is tailored to assess dark side personality traits at work. The HDS is a measurement to assess how individuals behave when they are stressed. It targets maladaptive personalities dealing with psychopathology and normal personality in occupational settings. It is based on the DSM-IV and aims to assess Cluster A, Cluster B and Cluster C disorders (American Psychiatric Association, 2013). Cluster A includes so-called odd disorders which are Paranoid, Schizoid and Schizotypal personality disorders. Cluster $\mathrm{C}$ can be categorized into anxious and fearful disorders which are described as Avoidant personality disorders. Hogan's items that measure Cluster A disorders are Excitable, Sceptical, Cautious, Reserved and Leisurely. Bold, Mischievous, Colourful and Imaginative are items that measure Cluster B disorders and Diligent and Dutiful are aimed to measure Cluster $\mathrm{C}$ disorders.

The eleven themes get assessed by a 168-item survey (Hogan \& Hogan, 2001; Hogan \& Hogan, 1997; Spain, Harms, \& LeBreton, 2014). The items are loading on three factors which are MovingAway, Moving Against and Moving Towards Others. According to Horney (1950) the Moving Away factor is a coping mechanism to avoid feelings of anxiety by withdrawing oneself from social situations. Someone who is scoring high on the Moving Against factor has hostility and trust issues and tries to minimise them by having power and control. The third trend Moving Towards includes the need to please everyone and ignoring one's own need (see Table 1).

Clifton, Turkheimer, \& Oltmanns (2009) conducted a study with military recruits and found that measures of centrality and degree connectivity were positively correlated with Narcissistic and Histrionic Personality Disorders. In addition, they were negatively related to Avoidant, Schizoid and Schizotypal Personality Disorders. Studies indicated that scoring high on sub-clinical psychopathy dimensions was positively correlated with creativity, good strategic thinking and communication skills (Babiak, Neuman, \& Hare, 2010) as well as entrepreneurship (Akhtar, Ahmetoglu, \& Chamorro-Premuzic, 2013).

\subsection{The Current Study}

The current study used SNA methodology to investigate the links between dark side personality traits and social networks. In order to find out which personality factors interact with social network characteristics, the study used a number of network dimensions, including friendship, advice and innovation networks.

Centrality measures indicate a person's importance in a network and ability to control information flow. Therefore, Excitable (H1a), Mischievous (H1b) and Colourful (H1c) personality types would be located more centrally within the network, reflecting a desire to use interpersonal networks to influence/exploit others. 
Table 1. Description of axis 2 of DSM-IV and Horney's theory.

\begin{tabular}{llc}
\hline DSM & Horney & Hogan
\end{tabular}

Cluster A (odd disorders)

- Paranoid personality disorder: characterised by a pattern of irrational suspicion and mistrust of others, interpreting motivations as malevolent

- Schizoid personality disorder: lack of interest and detachment from social relationships, apathy and restricted emotional expression

- Schizotypal personality disorder: a pattern of extreme discomfort interacting socially, distorted cognitions and perceptions
Moving Away from People

- The need for self-sufficiency and independence; while most desire some autonomy, the neurotic may simply wish to discard other individuals entirely.

- The need for perfection; while many are driven to perfect their lives in the form of well-being, the neurotic may display a fear of being slightly flawed.

- Lastly, the need to restrict life practices to within narrow borders; to live as inconspicuous a life as possible.
Moving Away from People

Excitable Moody and hard to please; intense but short-lived enthusiasm for people, projectsor things

Sceptical: Cynical, distrustful and doubting others' true intentions

Cautious: Reluctant to take risks for fear of being rejected or negatively evaluated

Reserved: Aloof, detached and uncommunicative; lacking interest in or awareness of the feelings of others

Leisurely: Independent; ignoring people's requests and becoming irritated or argumentative if they persist

Moving Against People

Bold: Unusually self-confident; feelings of grandiosity and entitlement; over valuation of one's capabilities

Mischievous: Enjoying risk taking and testing the limits; needing excitement; manipulative, deceitful, cunning and exploitative

Colourful: Expressive, animated and dramatic; wanting to be noticed and needing to be the centre of attention Imaginative Acting and thinking in creative and sometimes odd or unusual ways

\section{Cluster C (anxious or fearful disorders)}

- Avoidant personality disorder: pervasive feelings of social inhibition and inadequacy, extreme sensitivity to negative evaluation

- Dependent personality disorder: pervasive psychological need to be cared for by other people

- Obsessive-compulsive personality disorder (not the same as obsessive-compulsive disorder): characterised by rigid conformity to rules

\section{Moving Toward People}

- The need for affection and approval; pleasing others and being liked by them

- The need for a partner; one whom they can love and who will solve all problems
Moving Toward People

Diligent: Meticulous, precise and perfectionistic, inflexible about rules and procedures; critical of others

Dutiful: Eager to please and reliant on others for support and guidance; reluctant to take independent action or to go against popular opinion

Note: Reprinted from Backstabbers and bullies: How to cope with the dark side of people at work (pp. 133-135) by Furnham (2015). Bloomsbury Publishing. Reprinted with permission. 
Reserved ( $\mathrm{H} 2 \mathrm{a})$ and Cautious $(\mathrm{H} 2 \mathrm{~b})$ personality types would avoid the central positions in a network due to social inhibition and aloofness that is commonly associated with these personality types. It will also be predicted that Sceptical $(\mathrm{H} 2 \mathrm{c})$, Dutiful $(\mathrm{H} 2 \mathrm{~d})$ and Diligent $(\mathrm{H} 2 \mathrm{e})$ would correlate negatively with SNA centrality measures.

\section{Method}

\subsection{Participants}

Ethical committee approval was sought and received. Data were collected from a intact department of an engineers working in a firm in London. It is important in this research to study stable teams/groups of individuals who have worked together for some time. Participation in the study was voluntary. In total, 31 out of 40 participants (20 female) took part in the study (77\% response rate). The mean age was $27.10(\mathrm{SD}=15.89)$. Participants completed the measures as part of an internal employee consultancy project.

\subsection{Measures}

\subsubsection{Social Networks}

The data were collected on a number of network ties: innovation, friendship relations, and advice. The study employed a roster method, in which the respondents were asked to place checks next to the names of the people that they considered important for each network. The presented names were generated from the department employees worked in. For example, participants were asked who were the people that they would consider going to in order to discuss an innovative idea (to generate an innovation network). Other network questions included: "Whom would you consider a personal friend?" (friendship network); "Whom might you go for help and advice?" (advice).

\subsubsection{Hogan Development Survey (HDS; Hogan, \& Hogan, 1997)}

Dark Side Personality was assessed which the HDS, which includes 168 items. The internal reliability of the measure has been reported to be good, with Cronbach's alphas ranging from 0.50 to 0.80 (average of 0.64 ) and test-retest reliabilities over a three-month period ranging from 0.50 to 0.80 (average of 0.68 ) (Hogan \& Hogan, 1997).

\subsection{Procedure}

Participants completed all measures online. Each participant who agreed to take part in the survey received a personalised link to complete demographic (tenure, age and sex) and social network survey, which was generated by the Socilyzer platform (socilyzer.com). In the description to the study, participants were informed that the completion of the study would take around 20 minutes.

\section{Results}

The network data was analyzed with UCINET software (Borgatti, Everett \& 
Freeman, 2002) which enabled to obtain indegree, outdegree and betweenness centrality SNA metrics.

Figure 1 visually represents the social network for the innovation question. Furthermore, it shows the HDS profiles of four network nodes or people in the team (two with the most central and two with the least central SNA characteristics). The HDS scores of for each of the eleven dark-side factors. The higher the score the more that derailer plays a part in that person's interpersonal style at work. Scores 75 or over suggests that these are risk factors for those individuals.

HDS scores for different themes are expressed as percentiles (see Table 2).

A statistically significant positive correlation between Friendship Outdegree and Excitable factors, $r=0.36, p<0.05$ was observed, which confirms H1a. Those people who scored high on Excitable also had more out-coming ties towards other actors in the friendship network (or they were more likely to indicate that they have more friends). The results demonstrate that people who were associated with expansiveness SNA friendship network measure were found to be scoring higher on Excitable scale. A very similar effect was found when predicting advice network. There was a statistically significant positive correlation between Outdegree and Excitable measures, $r=0.43, p<0.05$ which means that

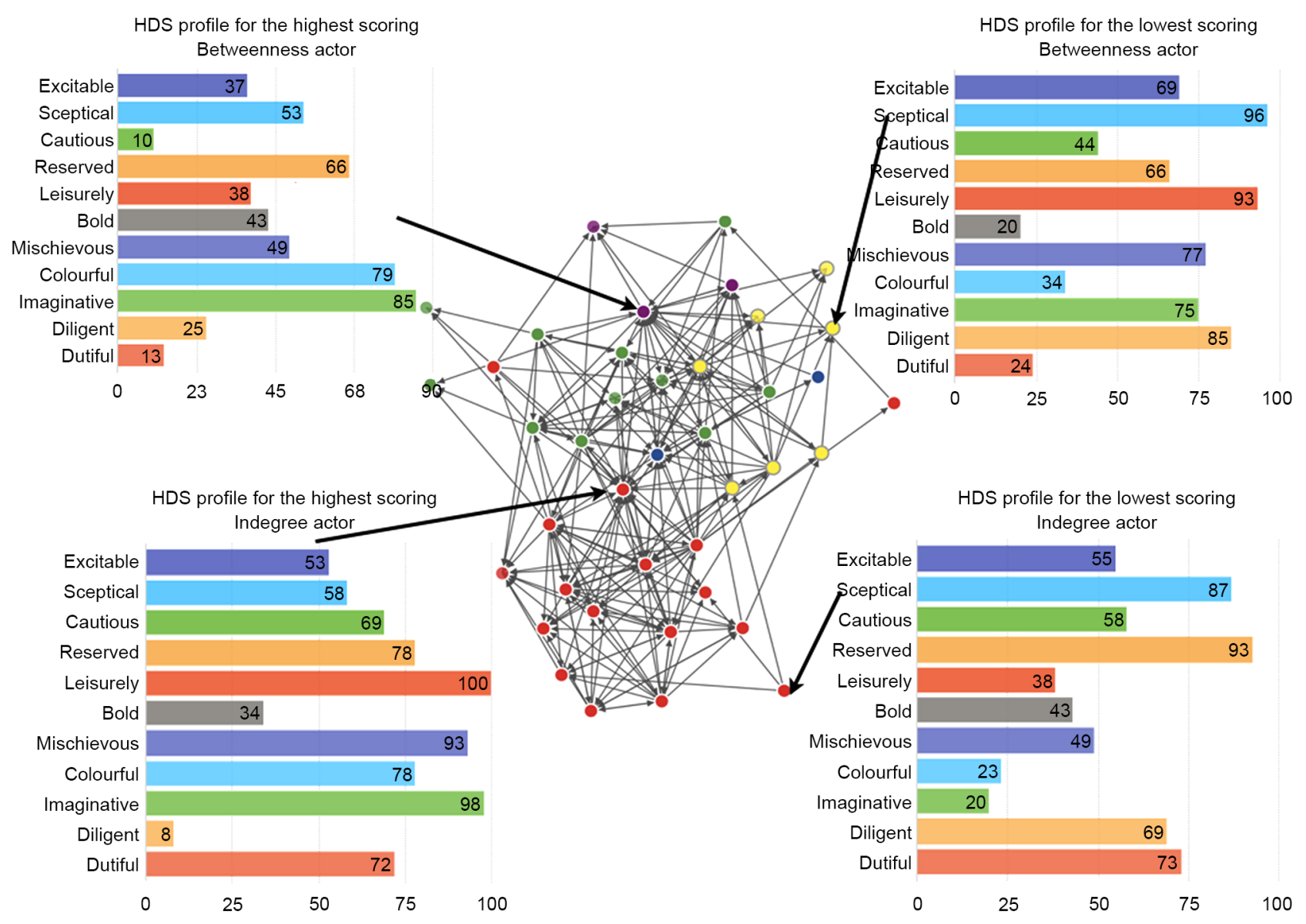

Figure 1. Visual representation of Social Network Analysis for innovation network and HDS profiles associated with the most and the least important network players as defined by Indegree and Betweenness SNA characteristics. Note: Different colours represent different cliques. 


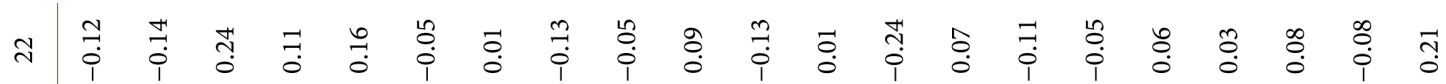

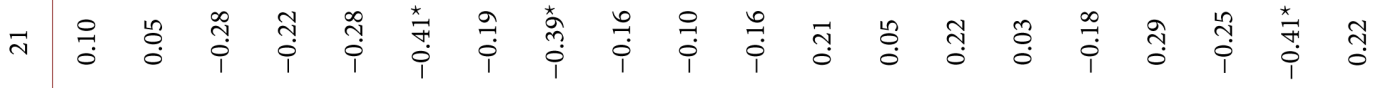

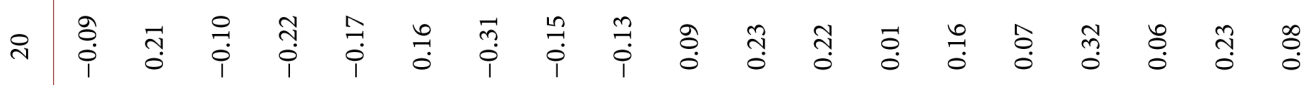

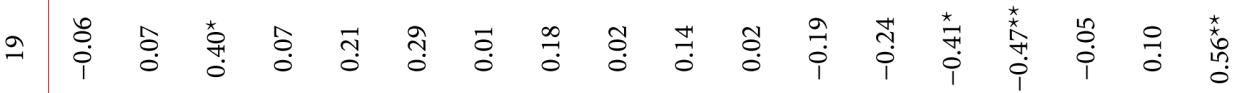

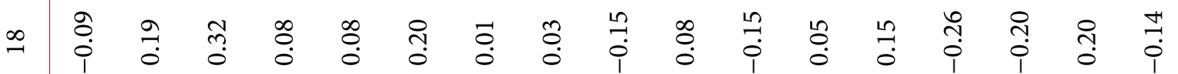

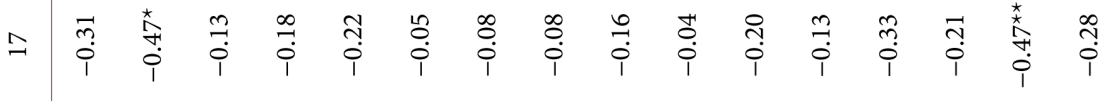

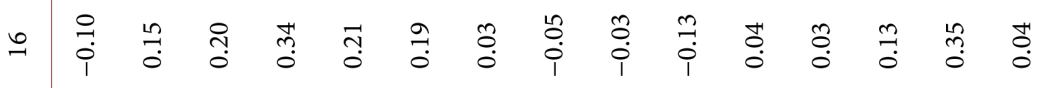

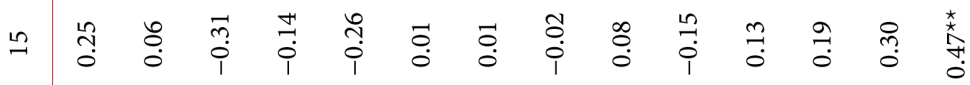

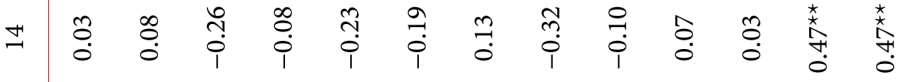

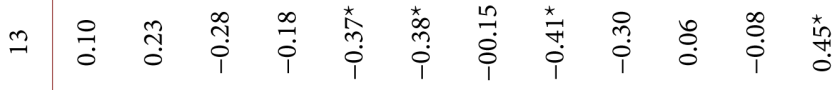

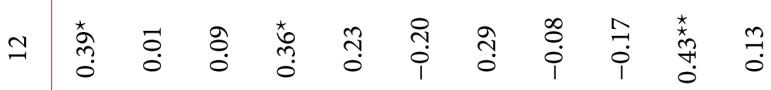

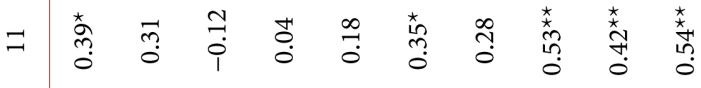

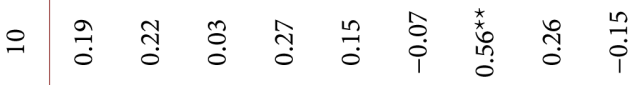

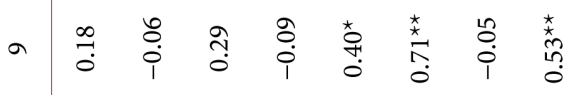

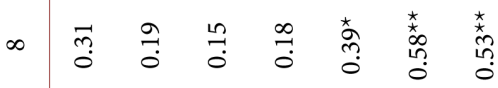

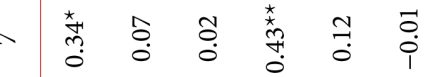

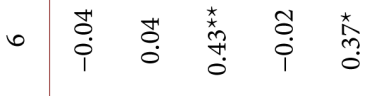

n $\mid$\begin{tabular}{llll}
$m$ & $\infty$ & \multirow{x}{*}{} & \multirow{2}{*}{} \\
0 & 0 & 0 & 0 \\
0 & 0 & 0 \\
0
\end{tabular}

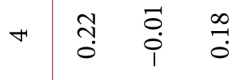

$m \mid \begin{array}{cc}2 & 0 \\ i & 0 \\ i & i\end{array}$

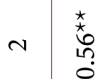


people who scored higher on Excitable factor were more likely to ask for help and advice from other team members.

We did not find any significant correlation between the trait Mischievous and SNA variables. Therefore, H1b was not supported.

However, a positive correlation between Friendship Outdegree and Colorful was observed which confirms H1c. Results indicated that participants who scored higher on Colorful also received more incoming ties in the friendship network.

H2: Negative correlations were expected among SNA centrality/degree and Reserved (H2a), Cautious (H2b), Sceptical (H2c), Dutiful (H2d) and Diligent $(H 2 e)$. Reserved and Cautious personality traits did not correlate significantly with any SNA variables. Therefore, $\mathrm{H} 2 \mathrm{a}$ and $\mathrm{H} 2 \mathrm{~b}$ were not supported but there was support for H2c. A significant correlation was observed between Friendship Betweenness and Sceptical, $r=-0.37, p<0.05$.

The results demonstrate that the higher people scored on Sceptical HDS factor, the less likely they were to occupy a central position in a friendship network, or vice versa. A very similar effect was observed when predicting Innovation Betweenness. the more participants scored on Sceptical scale, the less likely they were to tie groups together (or vice versa), as demonstrated by the statistically significant negative correlation between Sceptical factor and Innovation Betweenness, $r=-41, p<0.05$. Additionally, Sceptical personality type correlated negatively with Innovation Indegree, $r=-0.38, p<0.05$. Participants who scored higher on this personality factor also tended to receive less incoming ties in the innovation network. In other words, those who were popular when it came to discussing innovative ideas, were found to be scoring lower on the Sceptical factor.

Dutiful did not correlate significantly with any SNA variables, which was not in line with $\mathrm{H} 2 \mathrm{~d}$. We found a negative correlation between the factor Diligent and Innovation Indegree, $r=-0.41, p<0.05$. The higher participants scored on Diligent, the less incoming ties they received in the innovation network. Furthermore, Diligent correlated negatively with Innovation Betweenness, which means that individuals who secured central positions in the innovation network, tended to score lower on the Diligent HDS theme. Therefore, the results confirm H2e.

In order to test predictive validity of HDS personality factors, various multiple regression models were run with demographic variables in the first step, personality factors in the second step and SNA measures as dependent variables. However, none of the analysis revealed significant results.

\section{Discussion}

Overall, the results demonstrated that SNA characteristics had good predictive validity and some support was found for the generated hypotheses. Firstly, some HDS personality factors were positively related to the SNA characteristics. Specifically, Excitable HDS theme was positively related to friendship and advice 
network SNA characteristics; whereas, Colourful HDS theme was positively related to friendship network dynamics. Secondly, Sceptical personality trait influenced friendship and innovation networks negatively; whereas, Diligent factor negatively influenced innovation network SNA measures.

The presented findings extend the previous research (Klein et al., 2004, Mehra et al., 2001) of how personality factors affect social network characteristics by looking at how "negative" personality traits influence individuals' social structural worlds.

The results indicated that Excitable contextual personality factor was positively related to the Outdegree measures of friendship and advice networks. People who scored higher on this personality dimension tended to say that they have more friends as well as seek help and advice from others more often. Even though Clifton et al. (2009) did not find this factor to be related to any social network characteristic, the result is not surprising given that this personality trait is associated with enthusiasm, passion and interest (even if it is often short lived).

Another positive relationship was observed between the Indegree and Colorful (Histrionic) HDS theme for the friendship network. People scoring high on the Colorful theme tended to be more popular in the friendship network. That is, people with this personality profile tended to attract other people towards them in the organisation. The finding supports the hypothesis and its demonstrated that individuals who score high on Colorful scale have a desire to be noticed and feel the need to be at the centre of attention. In other areas of research, it has been established that high scores of Colorful dimension positively predicted occupational abilities (Furnham, Trickey, \& Hyde, 2012) and reduced the number of years it took to get promoted (Furnham, Crump, \& Ritchie, 2013).

Results also indicated that Colorful was positively related to the Betweenness measure in the friendship network and Indegree measure for Innovation. This pattern of results applied to Mischievous HDS factor as indicated by small and medium effect sizes for Innovation and Friendship Indegree measures, respectively. The results confirmed the previous finding that being manipulative is related to innovation potential (Zibarras et al., 2008).

The sceptical personality trait was found to correlate negatively with Indegree and Betweenness measures of innovation network. People scoring high on this scale inhibited innovation processes in a team network by not allowing other team members to come to them to discuss innovative ideas and were less likely to become central players in the innovation network (or less likely to become gatekeepers of innovative information). This could be due to the cynicism and distrustful nature often found in people with Sceptical personalities, and, also, due to their tendency to interpret neutral actions of others as negative or malevolent. Even though Clifton et al. (2009) found that Paranoid PD correlated positively with Outdegree measure, the current result is not surprising given the evidence that Sceptical personality traits tended to be correlated negatively with work success (Furnham et al., 2012). 
The current findings show a similar pattern of relationship between friendship Betweenness measure and Sceptical personality trait. That is, people with high Sceptical personality traits were less likely to act as links of different "cliques" in the friendship network. Their distrustful personality traits did not allow them to become central players in the friendship network. In other words, people with a highly pronounced Sceptical trait were more likely to possess peripheral positions in the friendship network (see Figure 1 for illustration).

Another "dark" personality trait that possible inhibits innovation processes in the corporate world is the Diligent characteristic. As with the Sceptical quality, people with the Diligent trait seem to be at the periphery of innovation network. They were less likely to become central players or information gatekeepers when it came to discussing innovative ideas. In addition, highly scoring Diligent people were less likely to seek others' help when it came to discussing novel opinions. It is possible that their perfectionist nature and desire to control everything that happens inhibit new ideas coming towards them. People scoring high on this trait are known for their rigidity towards rules and regulations, all of which might hinder their lateral thinking and imaginative approach to problem solving. This finding is consistent the evidence of increased psychological flexibility being associated with labour market growth, productivity, and ability to adapt to fierce and competitive markets (Nicoletti \& Scarpetta, 2003; Malhotra, Grover, \& Desilvo, 1996). It also supports the previous findings of highly dependent individuals being unable to poses structural hole positions in networks (Burt et al., 1999 ) and perfectionism correlating negatively with innovation potential (Zibarras, Port, \& Woods, 2008).

The study has limitations which possibly had an impact on the results. The sample included only employees who were working in an engineer firm, which makes it difficult to generalize the results. One of the main limitations is that the study design is cross-sectional. It is therefore not possible to make any judgements about causality. It is recommendable to do a longitudinal study on dark side personality traits and SNA in future. Another limitation is the use of selfreport measures. On the one hand, self-reports have the tendency to increase correlation and on the other hand participants might not answer the questions honestly.

\section{Conclusion}

In conclusion this study adds to the growing literature in two areas: the impact of dark-side variables at work (Furnham, 2015) and how personality affects social networks (Burt et al., 1998; Clifton et al., 2009). Studies such as this help to explain how and why certain dark-side factors relate to derailment. The Cluster A/Moving Away from people suggests that people with those traits would be less well networked with obvious implications for work performance. This study showed how sceptical, suspicious and vigilant individuals from this cluster tended to be poorly networked with all the benefits that they provide. The Cluster B/Moving Against other people traits are associated with leader- 
ship ambition and emergence but also derailment. This study highlighted the role of being colourful, melodramatic and cheerful in the development of social networks.

Some findings in this study are certainly worth further exploration particularly the role of Excitable in social networks. Excitable people can be very volatile, ambivalent and mercurial but if physically attractive as well as intelligence they may have a special allure. This suggests that to fully explore how, when and why dark-side factors are related to social network development, other factors need to be considered like the working history of the group as well as the social and task competency of each individual in that group.

\section{References}

Akhtar, R., Ahmetoglu, G., \& Chamorro-Premuzic, T. (2013). Greed Is Good? Assessing the Relationship between Entrepreneurship and Subclinical Psychopathy. Personality and Individual Differences, 54, 420-425.

https://doi.org/10.1016/j.paid.2012.10.013

American Psychiatric Association (2000). Diagnostic and Statistical Manual of Mental Disorders (4th Text Revision). Washington DC: American Psychiatric Association. https://doi.org/10.4135/9781483325385.n7

Babiak, P., Neumann, C. N., \& Hare, R. D. (2010). Corporate Psychopathy: Talking the Walk. Behavioral Sciences and the Law, 28, 174-193. https://doi.org/10.1002/bsl.925

Brass, D. J., Galaskiewicz, J., Greve, H. R., \& Tsai, W. (2004). Taking Stock of Networks and Organizations: A Multilevel Perspective. Academy of Management Journal, 47, 795-817. https://doi.org/10.2307/20159624

Borgatti, S. P., Everett, M. G., \& Freeman, L. C. (2002). Ucinet 6 for Windows: Software for Social Network Analysis. Harvard, MA: Analytic Technologies.

Burt, R. (1987). Social Contagion and Innovation, Cohesion versus Structural Equivalence. American Journal of Sociology, 92, 1287-1335. https://doi.org/10.1086/228667

Burt, R., Janotta, J., \& Mahoney, J. T. (1998). Personality Correlates of Structural Holes. Social Networks, 20, 63-87. https://doi.org/10.1016/S0378-8733(97)00005-1

Clifton, A., Turkheimer, E., \& Oltmanns, F. (2009). Personality Disorder in Social Networks: Network Position as a Marker of Interpersonal Dysfunction. Social Networks, 31, 26-32. https://doi.org/10.1016/j.socnet.2008.08.003

Contractor, N. S., \& Eisenberg, E. M. (1990). Communication Networks and Newmedia in Organizations. In J. Fulk, \& C. Steinfield (Eds.), Organizations and Communication Technology (pp. 143-172). Newbury Park, CA: Sage.

Furnham, A. (2015). Backstabbers and Bullies: How to Cope with the Dark Side of People at Work. London: Bloomsbury Publishing.

Furnham, A., Trickey, G., \& Hyde, G. (2012). Bright Aspects to Dark Side Traits: Dark Side Traits Associated with Work Success. Personality and Individual Differences, 52, 908-913. https://doi.org/10.1016/j.paid.2012.01.025

Furnham, A., Crump, J., \& Ritchie, W. (2013). What It Takes: Ability, Demographic, Bright and Dark Side Trait Correlates of Years to Promotion. Personality and Individual Differences, 55, 952-956. https://doi.org/10.1016/j.paid.2013.07.469

Goldberg, L. R. (1990). An Alternative "Description of Personality": The Big-Five Factor Structure. Journal of Personality and Social Psychology, 59, 1216-1229. 
https://doi.org/10.1037/0022-3514.59.6.1216

Hogan, R., \& Hogan, J. (1997). Hogan Development Survey Manual. Tulsa, OK: Hogan Assessment Systems.

Hogan, R., \& Hogan, J. (2001). Assessing Leadership: A View from the Dark Side. International Journal of Selection and Assessment, 9, 40-51.

https://doi.org/10.1111/1468-2389.00162

Horney, K. (1950). The Collected Works of Karen Horney: Self Analysis. Neurosis and Human Growth (Vol. 2). New York, NY: W. W. Norton \& Company.

Kalish, Y., \& Robins, G. (2006). Psychological Predispositions and Network Structure: The Relationship between Individual Predispositions, Structural Holes and Network Closure. Social Networks, 28, 56-84. https://doi.org/10.1016/j.socnet.2005.04.004

Kanfer, A., \& Tanaka, J. S. (1993). Unraveling the Web of Personality Judgments: The Influence of Social Networks on Personality Assessment. Journal of Personality, 61, 711738. https://doi.org/10.1111/j.1467-6494.1993.tb00788.x

Kim, Y., Choi, T. Y., Yan, T., \& Dooley, K. (2011). Structural Investigation of Supply Networks: A Social Network Analysis Approach. Journal of Operations Management, 29, 194-211. https://doi.org/10.1016/j.jom.2010.11.001

Klein, K., Lim, B., Saltz, J., \& Mayer, D. (2004). How Do They Get There? Anexamination of the Antecedents of Centrality in Team Networks. Academy of Management Journal, 47, 952-963. https://doi.org/10.2307/20159634

Malhotra, M., Grover, V., \& Desilvio, M. (1996). Reengineering the New Product Development Process: A Framework for Innovation and Flexibility in High Technology Firms. Omega, 24, 425-441. https://doi.org/10.1016/0305-0483(96)00007-2

Mehra, A., Kilduff, M., \& Brass, D. J. (2001). The Social Networks of High and Low Self-Monitors: Implications for Workplace Performance. Administrative Science Quarterly, 46, 121-146. https://doi.org/10.2307/2667127

Moreno, J. (1953) Who Shall Survive? Foundations of Sociometry, Group Psychotherapy and Sociodrama. Beacon, NY: Beacon House.

Nicoletti, G., \& Scarpetta, S. (2003) Regulation, Productivity and Growth: OECD Evidence. Economic Policy, 18, 9-72. https://doi.org/10.1111/1468-0327.00102

Schweizer, T. (1988). Detecting Positions in Networks: A Formal Analysis of Loose Social Structure in Rural Java. American Anthropologist, 90, 944-951.

https://doi.org/10.1525/aa.1988.90.4.02a00130

Spain, S. M., Harms, P., \& LeBreton, J. M. (2014). The Dark Side of Personality at Work. Journal of Organizational Behavior, 35, S41-S60. https://doi.org/10.1002/job.1894

Tichy, N., Tushman, M., \& Fombrun, C. (1979). Social Network Analysis for Organizations. Academy of Management Review, 4, 507-519.

Wasserman, S., \& Faust, K. (2009). Social Network Analysis: Methods and Applications. Cambridge: Cambridge University Press.

Wrzus, C., Hänel, M., Wagner, J., \& Neyer, F. J. (2013). Social Network Changes and Life Events across the Life Span: A Meta-Analysis. Psychological Bulletin, 139, 53. https://doi.org/10.1037/a0028601

Zhu, X., Woo, S., Porter, C., \& Brzezinski, M. (2013). Pathways to Happiness: From Personality to Social Networks and Perceived Support. Social Networks, 35, 382-393. https://doi.org/10.1016/j.socnet.2013.04.005

Zibarras, L. D., Port, R. L., \& Woods, S. A. (2008). Innovation and the "Dark Side" of 
Personality: Dysfunctional Traits and Their Relation to Self-Reported Innovative Characteristics. The Journal of Creative Behavior, 42, 201-215.

https://doi.org/10.1002/j.2162-6057.2008.tb01295.x

Submit or recommend next manuscript to SCIRP and we will provide best service for you:

Accepting pre-submission inquiries through Email, Facebook, LinkedIn, Twitter, etc. A wide selection of journals (inclusive of 9 subjects, more than 200 journals)

Providing 24-hour high-quality service

User-friendly online submission system

Fair and swift peer-review system

Efficient typesetting and proofreading procedure

Display of the result of downloads and visits, as well as the number of cited articles Maximum dissemination of your research work

Submit your manuscript at: http://papersubmission.scirp.org/

Or contact psych@scirp.org 